\title{
Analysis of labour market needs for engineers with enhanced knowledge in sustainable renewable energy solutions in the built environment in some Asian countries
}

\author{
Luca Cioccolanti ${ }^{*}$, Matteo Moglie ${ }^{1}$, Khamid Mahkamov ${ }^{2}$, Halime Paksoy ${ }^{3}$, Chao Chen ${ }^{4}$, Jie Lin $^{4}$, Caiyun $\mathrm{Li}^{4}$, Yong \\ Guan $^{5}$, Wenhe Zhou ${ }^{5}$, Ermira Abdullah ${ }^{6}$, Mohd Amran Mohd Radzi ${ }^{6}$, Suhaidi Shafie ${ }^{6}$, Zainal Alimuddin ${ }^{7}$, Mohamad \\ Yusof Idroas $^{7}$, Teoh Yew Heng ${ }^{7}$, Mohd Azmier Ahmad ${ }^{7}$, Muhamad Azman Miskam ${ }^{7}$, Kwanchai Kraitong ${ }^{8}$, Wongkot \\ Wongsapai $^{9}$, Chatchawan Chaichana ${ }^{9}$, Det Damronsak $^{9}$
}

\author{
${ }^{1}$ Centro di Ricerca Energia Ambiente e Territorio (CREAT), Università eCampus, Via Isimbardi 10, 20060 Novedrate (CO), Italy \\ ${ }^{2}$ Department Mechanical and Construction Engineering, Northumbria University, Newcastle upon Tyne NE1 8ST, UK \\ ${ }^{3}$ Chemistry Department, Arts and Sciences Faculty, Cukurova University, Adana, Turkey \\ ${ }^{4}$ College of Architecture and Civil Engineering, Beijing University of Technology, Beijing 100124, PR China \\ ${ }^{5}$ Lanzhou Jiaotong University, West Anning Road 88, Lanzhou 730070, PR China \\ ${ }^{6}$ Faculty of Engineering, Univeristi Putra Malaysia, 43400 Selangor Darul Ehsan, Malaysia \\ ${ }^{7}$ School of Mechanical Engineering, Universiti Sains Malaysia, 14300 Nibong Tebal, Penang, Malaysia \\ ${ }^{8}$ Department of Mechanical Engineering, Faculty of Engineering, Naresuan University, Phitsanulok 65000, Thailand \\ ${ }^{9}$ Faculty of Engineering, Chiang Mai University, 239 Suthep Chiang Mai 50200, Thailand
}

\begin{abstract}
Despite the rapid growth in the uptake of renewable energy technologies, the educational profile and the skills gained at University level do not always comply with the practical needs of the organisations working in the field. Furthermore, even though the residential sector has very high potential in curbing its $\mathrm{CO}_{2}$ emissions worldwide thus meeting the challenging goals set out by the international agreements, such reduction has been limited so far. Within this context, the 'Skybelt' project, co-funded by the EU under the framework of the Erasmus + programme aims at enhancing in several Universities of Asia and Europe the engineering skills of students of all level for application of sustainable renewable energy solutions in the built environment. With the target of increasing the employability of graduates and the impact of the project, a survey on the labour market needs for specialists with enhanced knowledge and skills in the topic of the project has been conducted in the related Asian countries. Hence, relevant industries, labour market organisations and other stakeholders have been interviewed and the main results of this analysis is reported in the present paper. As first outcome of this activity, the obtained results have been considered in the selection of the modules to be improved according to a student centred study approach.
\end{abstract}

\section{Introduction}

The increasing energy demand, the catastrophic consequences of climate changes and the limited conventional energy sources have stressed the importance of renewable energy technologies to promote a sustainable development. Sustainable development, indeed, is defined as "meeting the needs of the present without compromising the ability of future generations to meet their needs" [1].

Since 2001 the power capacity of renewables has grown annually, but in 2018 the added net capacity of renewables around the world has been the same as in 2017 (about $180 \mathrm{GW}$ ) [2]. In order to achieve the ambitious goals set out by the Paris Agreement an annual grow of over $300 \mathrm{GW}$ is needed from 2018 to 2030 to curb $\mathrm{CO}_{2}$ emissions worldwide. Therefore, it is evident that at global level further efforts are still needed to promote the uptake of renewable energy technologies thus supporting a sustainable development.

Transforming the global energy system to $100 \%$ renewable requires firstly a strong workforce of renewable energy and related sustainability professionals and practitioners. In the recent years, the labour market related to green economy has been boosted, creating an ever-increasing demand of linked employment. For example, according to Bowen et al. [3] $19.4 \%$ of US workers could be considered directly or

* Corresponding author: luca.cioccolanti@uniecampus.it 
indirectly occupied in jobs related to green economy. In the context of green economy, renewable energies play a key role in the energy transition for carbon reduction. In [4], Fragkos and Paroussos investigated the net employment impacts of the EU energy sector transformation towards a renewable energy one finding that this low-carbon transition would reallocate about $1.3 \%$ of the EU's workforce across sectors by 2050 . At the same time, in order to support such transformation also an informed public is of paramount importance. For this reason, in [5] Middleton provided a number of general techniques to enhance education at all levels. Indeed, as recently reported by Wojuola and Alant [6] for the case of the Nigeria country, the public awareness of a sustainable development is still limited and there is a need of educational curricula incorporating themes related to renewable energy and sustainable livelihood.

So far, several studies have been conducted at national level on this issue [7-9]. However, the knowledge and skills gained at University level do not always fit with the practical needs of the industries thus extending the formation period of the new employees and decreasing the consequent benefit-cost ratio. For these reasons, educating green collars workers to develop and promote renewable energy technologies with technical, professional and managerial abilities to satisfy the energy demand in a sustainable way is among the mission of many university programmes worldwide. Beside a cleaner energy production, also energy efficiency is another pillar for reducing carbon emissions worldwide. In particular, the building sector which in Europe accounts for about $40 \%$ of the final energy consumption and $36 \%$ of $\mathrm{CO}_{2}$ emissions [10] has a significant room of improvement in curbing its share. In the rest of the world, despite such figures may differ, the high impact of the building sector in the energy consumption is significant as well.

In this context, the 'Skybelt' project [11], co-funded by EU under the framework of the European Union's Erasmus + programme and coordinated by eCampus University [12] aims at enhancing the skills of engineering students at all levels for application of sustainable renewable energy solutions to be integrated into the built environment in several Universities of Asia and Europe. In particular, 3 EU Universities in Italy, United Kingdom and Turkey, and 6 Asian Universities in China, Maleysia and Thailand are collaborating in this project. All of them experience an increasing interest in offering up-to-date and advanced courses on renewable energy with special focus on their integration into the built environment thereby indirectly contribute to meeting the ambitious targets set out for climate change mitigation at International level.

With reference to these countries, China, with its colossal population and economics, is fighting for a greener future. Extremes in environmental pollutions have been obvious for many years across all Chinese territory, especially affecting its cities, small and large. Pollutions were due to the excessive use of fossil fuels, especially coal, in both industrial/agricultural and built environment sectors. One of the effective ways to tackle the looming environmental disaster is to make full use of renewable energy technologies by integrating them into residential, commercial and industrial buildings. Therefore, since some years the Chinese Government actively promotes the use of renewable energy. At the end of 2019, the installed capacity of renewable energy power generation in China was 794 million kilowatts, accounting for $39.5 \%$ of the total installed power capacity [13]. According to China's National Energy Strategy [14] non-fossil energy will account for $20 \%$ of primary energy consumption in 2030 . Hence, in order to effectively achieve such goal a new type of specialists with a deep knowledge of the state-of-the-art and technological advances is required.

In Malaysia, despite large fossil fuel resources the Government is pushing for renewable energy as a cleaner alternative solution. Subsequent new energy policies and programmes aim at providing energy security and sustainability, efficient resource utilization and environmental safeguarding through increased renewable energy technologies which require qualified graduates in this subject area.

Eventually, in Thailand energy is imported for approximately $50 \%$ of country energy consumption which highlights the need for exploring alternative energy sources based on renewables. Therefore, the Government is supporting the development and the application of large, small and micro-scale renewable energy systems also at building level through the longterm 22-year Alternative Energy Development Plan 2015-2036 with the final aim of promoting this transition.

Considering the strategic role of renewable energy solutions in these countries in the next future, a survey on the labour market needs for specialists with enhanced knowledge and skills in renewable energy technologies to be integrated into the built environment has been conducted and some of the results are reported in this paper.

\section{Methodology}

The modernized teaching methods and contents to be implemented in the 'Skybelt' project are designed based on a student centred approach following the agreements derived from the so called Bologna process. According to this, a study programme must have at its focus the satisfaction of the current and future market needs which are assessed by consulting relevant industries, stakeholders and other organizations that could be interested in the specific area. In case of engineers, high quality specialists in renewable energy engineering will be able to support governments, private organisations as well as corporate activities in the uptake of renewable energy technologies in the built environment thus contributing to the $100 \%$ renewable energy transition.

For these reasons, the partnership involved in the project has defined and presented to different stakeholders acting in this field a questionnaire with the objective of assessing the market demand and its training needs prior to any enhancement of the teaching contents and methods. In particular, industrial companies, NGOs as well as public and private organizations have been contacted as representative of 
the labour market for engineers in the different Asian countries. These organizations have been chosen because they both represent the different business activities in the renewable energy sector and they have previously shown a high interest in renewable energy research and education through frequent collaboration with the universities involved in the project. Therefore, they have been asked for assistance and advice based on their significant expertise in the energy field.

The questionnaire is divided into three parts. The first one asks for information about the company profile, its type of activity/interest in the renewable energy technologies with special focus to their integration into the built environment and its market extent. The second part, instead, focuses on the level of knowledge of their actual employees in the topic of the 'Skybelt' project. Eventually, the third part which is the major one aims at assessing the training needs of the labour market in terms of willingness of the company to hire Bachelor, Master and/or Ph.D. engineers with enhanced knowledge in the topic of the project in the next years, the rough estimation of their numbers for each educational level, the main topic of renewable energy specialization and the related knowledge and skills required. Moreover, this part evaluates also the potential engagement of the interviewed institution in the 'Skybelt' project in hosting students for their internships, in enhancing the teaching content or in taking part to specific project activities.

\section{Results and discussion}

For the scope of the survey, more than 120 organisations have been identified. So far, 107 organisations have answered to the questionnaire with almost $73 \%$ of those located in China.

The initial questions were aimed at evaluating the current background of the organizations in terms of their size, market and type of activity involved in. At a global level, $15.4 \%$ of the organisations have fewer than 10 employees, around $29 \%$ were in the range of 10 to 50 employees, only $9.6 \%$ between 50 and $100,23.1 \%$ from 100 to 500 and the same percentage have more than 500 employees. With reference to the type of activity in the renewable energy sector, the overall result of the analysis has shown that the majority are involved in 'Design \& Engineering Development' and 'Research \& Development' as reported in Figure 1.

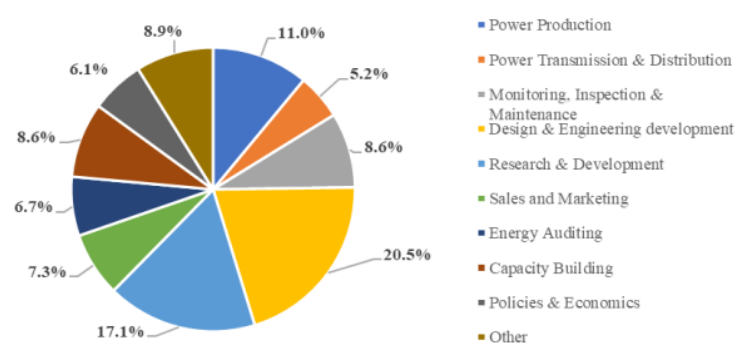

Fig. 1. Type of activity of the organisations on renewable energy
As regards the market, $50 \%$ of them are focused at international level.

In the second part of the questionnaire, the level of knowledge of the present employees is assessed. At global level, the organisations hire employees with different levels of qualification as reported in Table 1:

Table 1. Range of qualification of the present employees of the organisations.

\begin{tabular}{|c|c|}
\hline Qualification & Percentage \\
\hline Bachelor & $32.7 \%$ \\
\hline Master & $31.3 \%$ \\
\hline PhD & $26.1 \%$ \\
\hline Other & $10.0 \%$ \\
\hline
\end{tabular}

It is worth noticing that these percentages refer to the companies and not to the actual number of employees with a specific level of qualification. Moreover, such percentages change significantly when comparing different countries. For example, most of organisations in Thailand have employees with Bachelor degree in education $(48 \%)$ and only a reduced number with $\mathrm{PhD}$ (12\%) while almost $27 \%$ of Chinese organisations have employees with $\mathrm{PhD}$ level of education. With respect to their knowledge on renewable energy the following results have been obtained:

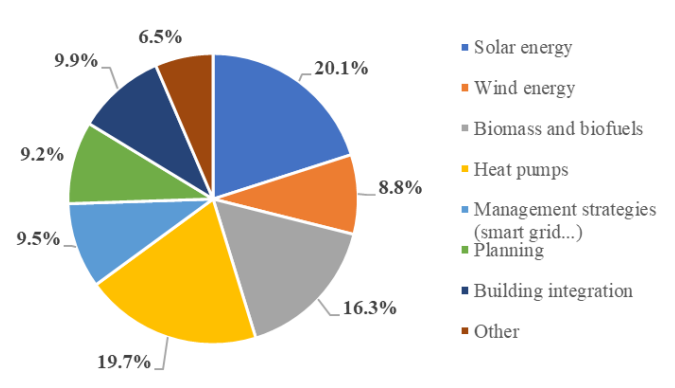

Fig. 2. Knowledge of present employees on renewable energy

Hence, most of them are working on solar energy technologies $(20.1 \%)$, heat pumps and biomass and biofuels. Focusing on the solar energy source, $41.9 \%$ have expertise on solar thermal, almost the same percentage on PV and an appreciable percentage of about $13.3 \%$ on Concentrated Solar Technologies (CST). As regards the application, most of them are dealing with heating (about 42.3\%) and electricity $(37.5 \%)$ and only a small percentage of about $12.5 \%$ with cooling.

In the third part of the questionnaire, the training needs of the organisations are assessed with the final aim of enhancing specific modules in the Partner countries Universities within the context of the 'Skybelt' project. 
Firstly, the main challenges that Sustainable Renewable Energy Technologies market is going to face in the next years is asked. Figure 3 shows the obtained results:

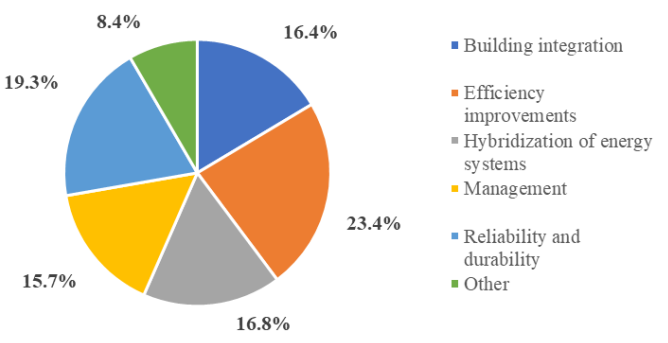

Fig. 3. Main challenges of Sustainable Renewable Energy Technologies market in the next years

Then, the interest of the organisations in recruiting new engineers in the near future is evaluated. At global level, $75 \%$ of the companies/organizations interviewed has shown the interest in employing new engineers in the next three years. Moreover, $72 \%$ of the overall organisations are interested in recruiting new engineers with enhanced knowledge and skills in renewable energy solutions for the built environment thus highlighting the potential of the 'Skybelt' project in the labour market. With respect to the level of education, the obtained results show that a consistent number of them require engineers with master degree (42\%). However, focusing on the potential numbers of new engineers with respect to the degree level, around 850 new engineers with bachelor degree are required while the number of engineers with master degree are much lower and in line with the number of $\mathrm{PhD}$ (more than 150 each). This result confirms the goodness of the 'Skybelt' project which aims at enhancing the engineering skills of students at all levels.

With respect to the required topic of knowledge of future employees on renewable energy it is obtained that expertise in the field of management strategies of renewable energies is also extensively required:

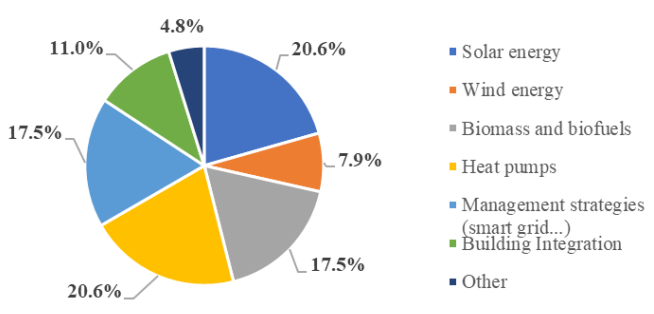

Fig. 4. Topic of knowledge of future employees on renewable energy

Finally, to those organisations which believed that enhanced modules in renewable energy solutions for the built environment should be taught at different levels in Universities additional feedbacks have been asked. More precisely, as regards the energy source remarkable interest has arisen with respect to solar energy, biomass and biofuel and waste heat as reported in Figure 5:

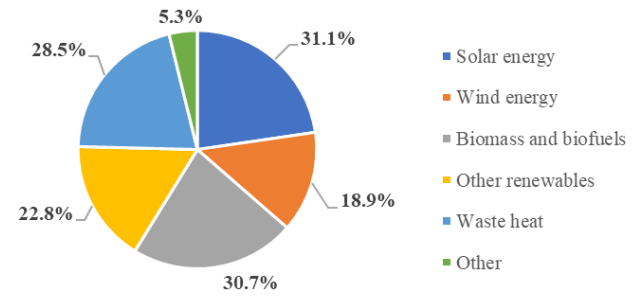

Fig. 5. Energy source of knowledge of future employees on renewable energy

With respect to the kind of application, the interest towards combined heat and power (CHP) and combined cooling heating and power (CCHP) is very remarkable thus proving the energy efficiency perspective.

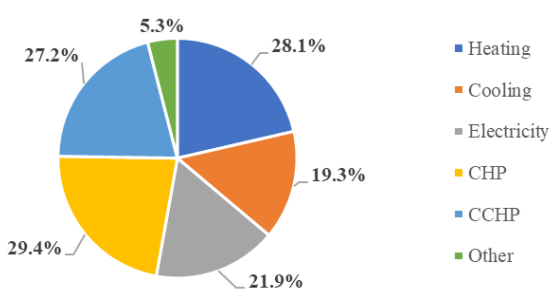

Fig. 6. Kind of application of knowledge of future employees on renewable energy

With reference to the kind of technology, most of the interest is addressed to heat pumps (25.4\%), solar thermal (24.6\%), PV (19.3\&), CST and boiler (18.4\% each) as reported in Figure 7 below:

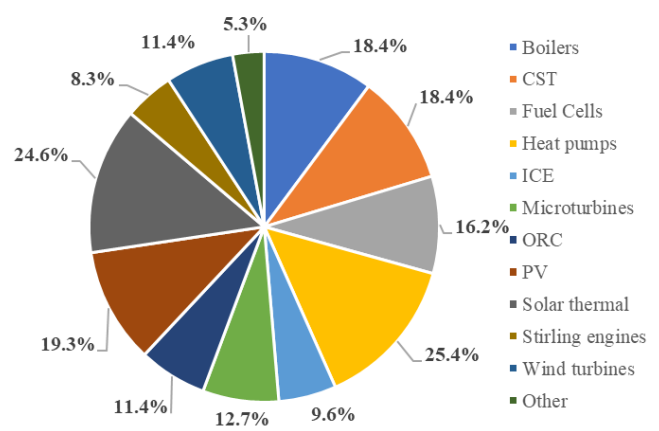

Fig. 7. Kind of technology of knowledge of future employees on renewable energy

Finally, with respect to the kind of expertise needed it has arisen that control and automation, data analysis and predictive control and energy storage are those mostly required as shown in Figure 8: 


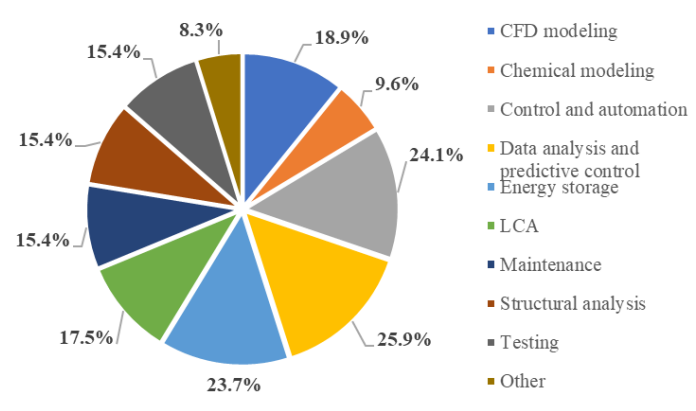

Fig. 8. Kind of expertise of future employees on renewable energy

Eventually, the third part of the questionnaire ends with some questions related to the willingness of the organisations of being part of the project network and cooperating in the activities of the project finding a positive approach of the companies in contributing to the impact of the 'Skybelt' project.

\section{Conclusions}

In the recent years, because of the increasing human capital requirement of the growing renewable energy sector many Universities worldwide are paying attention to this aspect and they are offering new study programmes in the field. Moreover, considering the high impact of the building sector in the energy consumption at global level, renewable energy solutions for the built environment may play a significant contribution in curbing $\mathrm{CO}_{2}$ emissions and de-carbonising the sector.

Within this context, the EU partially co-funded project 'Skybelt' aims at enhancing specific modules on renewable energy solutions for their integration into the built environment at all university level in some Asian Universities.

Since the satisfaction of the current and future labour market needs are fundamental for the modernization of engineering curricula, a survey on the labour market needs in specialists with enhanced knowledge in this field has been conducted by the members of the consortium in the partner countries, namely China, Malaysia and Thailand. Industrial, private and public organisations as well as NGOs have been interviewed as representative of the labour market in the energy sector. Results of the survey show that satisfaction of the knowledge of the current employees on renewable energy is limited especially at Bachelor degree level. At the same time, almost $72 \%$ of the interviewed organisations report their interest in recruiting new employees with enhanced knowledge and skills in renewable energy solutions for the built environment. In particular, solar technologies and heat pumps are the most required field of expertise. Furthermore, as regards the kind of expertise control and automation, data analysis and predictive control and energy storage are those mostly needed for the future employees thus providing useful insights into the specific modules to be enhanced under the scope of the 'Skybelt' project
This study is part of the "The Skybelt" Project, co-funded by the Erasmus + Programme of the European Union (agreement No 610258-EPP-1-2019-1-IT-EPPKA2-CBHEJP). The authors wish to thank also the organisations which kindly answered to the questionnaire.

\section{References}

1. WORLD COMMISSION ON ENVIRONMENT AND DEVELOPMENT; 1987;

2. Renewable capacity growth worldwide stalled in 2018 after two decades of strong expansion News - IEA Available online:

https://www.iea.org/news/renewable-capacitygrowth-worldwide-stalled-in-2018-after-twodecades-of-strong-expansion (accessed on Jun 5, 2020).

3. Bowen, A.; Kuralbayeva, K.; Tipoe, E.L. Characterising Green Employment: The impacts of 'greening' on workforce composition. Energy Econ. 2018.

4. Fragkos, P.; Paroussos, L. Employment creation in EU related to renewables expansion. Appl. Energy 2018.

5. Middleton, P. Sustainable living education: Techniques to help advance the renewable energy transformation. Sol. Energy 2018.

6. Wojuola, R.N.; Alant, B.P. Sustainable development and energy education in Nigeria. Renew. Energy 2019.

7. Ocetkiewicz, I.; Tomaszewska, B.; Mróz, A. Renewable energy in education for sustainable development. The Polish experience. Renew. Sustain. Energy Rev. 2017, 80, 92-97.

8. Kayahan Karakul, A. Educating labour force for a green economy and renewable energy jobs in Turkey: A quantitave approach. Renew. Sustain. Energy Rev. 2016, 63, 568-578.

9. Alawin, A.A.; Rahmeh, T.A.; Jaber, J.O.; Loubani, S.; Dalu, S.A.; Awad, W.; Dalabih, A. Renewable energy education in engineering schools in Jordan: Existing courses and level of awareness of senior students. Renew. Sustain. Energy Rev. 2016, 65, 308-318.

10. Energy performance of buildings directive Energy Available online: https://ec.europa.eu/energy/topics/energyefficiency/energy-efficient-buildings/energyperformance-buildings-directive_it (accessed on May 21, 2020).

11. SkyBelt Available online: http://skybelt.eu/ (accessed on Jun 8, 2020).

12. eCampus Available online: http://www.uniecampus.it/en/index.html (accessed on Jun 25, 2020).

13. National Energy Administration releases 2019 national renewable energy power development monitoring and evaluation report-China Power Net Available online:

http://www.chinapower.com.cn/xw/zyxw/2020 0520/19318.html (accessed on Jun 25, 2020).

14. 2019 National renewable power development 
monitoring and evaluation report $\mid$ China Energy Portal | 中国能源门户 Available online: https://chinaenergyportal.org/en/2019national-renewable-power-developmentmonitoring-and-evaluation-report/?tpedit=1\# (accessed on Jun 25, 2020). 